\title{
Determination Of The Mercury Content Of Lichens and Comparison To Atmospheric Mercury Levels In The South African Highveld Region
}

\author{
Andreas Trüe ${ }^{1}$, Nickolay Panichev ${ }^{2}$, Jonathan Okonkwo $^{3}$ and Patricia B.C. Forbes ${ }^{1,4^{*}}$ \\ ${ }^{1}$ CSIR, PO Box 395, Pretoria, 0001, South Africa \\ ${ }^{2}$ Department of Chemistry, Tshwane University of Technology, Private Bag X680, Pretoria, 0001, South Africa \\ ${ }^{3}$ Department of Environmental, Water and Earth Sciences, Tshwane University of Technology, Private Bag X680, \\ Pretoria, 0001, South Africa \\ ${ }^{4}$ Department of Chemistry, Faculty of Natural and Agricultural Sciences, University of Pretoria, Lynnwood Road, \\ Pretoria, 0002, South Africa, Email patricia.forbes@up.ac.za
}

\begin{abstract}
The concentration of mercury vapour in ambient air is routinely determined using specialised instruments. As an economical alternative, actively pumped Hopcalite sorbent tubes can be used to trap atmospheric mercury, which is subsequently analysed by cold vapour atomic absorption spectroscopy. Plant materials are also readily available in most regions and can be analysed to obtain information on time averaged atmospheric mercury levels.

Lichen and tree bark samples were collected in the cities of Pretoria and Witbank, dried and acid digested with subsequent cold vapour atomic absorption spectroscopy. Average mercury concentrations ranging from 74 to $193 \mu \mathrm{g} . \mathrm{kg}^{-1}$ were found in lichens from three Pretoria suburbs, whilst average $\mathrm{Hg}$ levels of 228 $\mu \mathrm{g} . \mathrm{kg}^{-1}$ were determined in lichens collected in Witbank. The average mercury concentration in tree bark was consistently lower than in lichens, with concentrations between 28 and $72 \mu \mathrm{g} \mathrm{kg}^{-1}$ determined in samples from three Pretoria suburbs and $75 \mu \mathrm{g} . \mathrm{kg}^{-1}$ determined in samples taken in Witbank. This study is the first in South Africa to determine mercury levels in lichens and tree bark.

Average total gaseous mercury concentrations in ambient air at the three Pretoria suburban sites, as determined by a semi-continuous spectroscopic method using Hopcalite sampling, ranged between 1.6 and $2.5 \mathrm{ng} \cdot \mathrm{m}^{-3}$, while an average of $1.7 \mathrm{ng} \cdot \mathrm{m}^{-3}$ was measured in Witbank over the sampling interval.
\end{abstract}

Keywords: atmospheric mercury, $\mathrm{Hg}$, lichens, Hopcalite, microwave digestion, tree bark, cold vapour atomic absorption spectroscopy

\section{Introduction}

Anthropogenic activity is a major contributor to the atmospheric mercury burden. Sources include coal fired power plants, incinerators, chloralkali plants and battery production plants (Pacyna \& Pacyna, 2002). Background atmospheric mercury levels of $1.3 \mathrm{ng} \cdot \mathrm{m}^{-3}$ have been measured in remote, non-exposed areas, with the volatility and relative inertness of the element contributing to its distribution in the atmosphere (Carpi, 1997). On the other hand, values above $30 \mathrm{ng} \cdot \mathrm{m}^{-3}$ have been reported in suburbs of the highly polluted city of Beijing during adverse weather conditions (Liu et al., 2002). Ambient total gaseous mercury (TGM) concentrations in background air average at around 1.5 ng. ${ }^{-3}$ worldwide (European Communities, 2002). South Africa has been rated as one of the largest emitters of mercury in the world with an estimated emission of 256 tons of mercury per annum (Pacyna et al., 2006), although a lower estimate of 62 tons was determined for 2006 (Masekoameng et al., 2010). These emissions are largely the result of the country's use of coal as a primary energy source, and the relative density of coal fired power plants in the Highveld region would thus be suggestive of a potentially high atmospheric mercury burden in this area. It is therefore important that local atmospheric $\mathrm{Hg}$ levels be determined to aid in the assessment of potential environmental impacts.

Semi-continuous emissions monitors (SCEMs), based on the amalgamation principle, are well established for the determination of atmospheric mercury. They are capable of almost real time measurements and their high sensitivity allows for the detection of atmospheric mercury even in remote, non-exposed areas (Ebinghaus et al., 1999). A combination of mercury preconcentration by amalgamation and detection by atomic fluorescence spectroscopy ensure high specificity of mercury SCEMs. Due to the complexity and size of such systems, analysers are difficult to move to new positions for shortterm monitoring and are usually installed in fixed monitoring stations. 
Hopcalite type sorbent tubes have long been used for monitoring of mercury vapours in the workplace where mercury concentrations in air far exceed environmental levels (Rathje et al., 1974). Actively pumped sorbent tubes are in use for personal monitoring, typically during an eight hour shift in industrial environments where mercury concentrations of up to $50 \mu \mathrm{g} \cdot \mathrm{m}^{-3}$ are permissible (NIOSH, 1994). The combination of sorbent tube and pump can easily be moved and installed and is stable to changes in the environment. Since the flow rate through a sorbent tube is limited (NIOSH, 1994), an increase in sensitivity to ambient environmental atmospheric mercury concentrations in the low ng. $\mathrm{m}^{-3}$ range (Ebinghaus et al., 1999) would have to be achieved through extending the exposure time. Due to the strong bond between mercury and the sorbent material (Health and Safety Executive, 2002), breakthrough effects are not likely to impede increasing the exposure time and thus the volume of air sampled.

The analysis of biological matrices provides time averaged levels of air pollutants as a result of long term exposure and may therefore be used as useful indicators of air pollution. Lichens are well studied biomonitors for atmospheric mercury because their slow growth, large surface area and lack of a root system make them good absorbers of airborne pollutants (Conti \& Cechetti, 2001). Lichens absorb nutrients and pollutants mainly through wet and dry deposition (Becnel et al., 2004), but may also lose the absorbed pollutants over time. It has been calculated that once pollution has subsided, metals that have been absorbed by lichens may take up to four years to be released from the lichen thallus until a new equilibrium is reached (Walther et al., 1990). A point source, such as a chloralkali production plant, has been shown to result in a clear mercury concentration gradient in lichens harvested at an increasing distance from the source (Sensen \& Richardson, 2002), although the mercury content in lichens may vary according to the host tree. It is therefore important that lichens are collected from the same host tree species. Monitoring of environmental pollution may be performed by either analysing lichens growing naturally in polluted areas or by transplanting lichens from non-exposed areas to polluted areas for a certain time. It has been suggested that transplanted lichens should be protected against direct rain exposure to avoid leaching of trapped heavy metals (Machado et al., 2006). In South Africa, lichens are starting to gain importance as environmental monitors with lead and manganese levels having been determined in lichens following the introduction of organo- manganese compounds in petrol as a replacement for lead additives (Forbes et al., 2009 and Monna et al., 2006). Heavy metals associated with dust originating from metal smelters have also been determined in lichens, tree bark and dust (Panichev \& McCrindle, 2004).

This study serves to determine the $\mathrm{Hg}$ levels in lichens growing in areas of the South African Highveld region for the first time. Samples were taken in areas which were expected to have higher $\mathrm{Hg}$ levels in ambient air, as well as in potentially less impacted areas. Total gaseous $\mathrm{Hg}$ concentrations were also determined in the sampling areas using a semi-continuous spectroscopic method based on sorbent sampling (Trüe et al., 2010) for comparative purposes.

\section{Materials and Methods}

\subsection{Sampling sites}

The Council for Scientific and Industrial Research (CSIR) is located in Pretoria's eastern suburb of Brummeria (Table 1). The premises are in an area with little vehicle traffic but highways are located approximately $0.5 \mathrm{~km}$ to the west and $1 \mathrm{~km}$ to the north and east of the sampling site. Mercury sorbent tubes (Anasorb C300, SKC International, Eighty-Four, PA, USA) protruded from a partially opened window approximately $10 \mathrm{~m}$ above ground level. It should be noted that ideal sampling sites at appropriate distances from buildings could not be realised due to the power supply needs of sampling pumps and for security reasons.

The suburb of Hatfield is located approximately 5 $\mathrm{km}$ to the west of the CSIR towards the city centre in an area with very high vehicle traffic volumes. Hatfield and the city centre are in a valley with mountain ridges to the north and south. Mercury sorbent tubes and pumps were installed on a flat rooftop, approximately $10 \mathrm{~m}$ above ground level.

The air monitoring station in Pretoria West, adjacent to a coal-fired power station, is situated a further $9 \mathrm{~km}$ to the west in an area with moderate vehicle traffic. Mercury sorbent tubes were installed in a secure shelter approximately $2 \mathrm{~m}$ above ground level.

The city of Witbank lies approximately $100 \mathrm{~km}$ to the east of Pretoria and its industry is dominated by steelworks and electricity production by coal fired power plants. Steel production sites are located approximately $6 \mathrm{~km}$ to the northwest and $14 \mathrm{~km}$ to the west of the sampling site in the city centre, while the closest of a number of coal-fired 
power plants in the area is situated approximately $10 \mathrm{~km}$ from the city limits to the south east, as seen in Figure 1. Lichen and bark samples were taken at the Witbank Golf Course situated centrally, but surrounded by schools, sports grounds and a cemetery. Mercury sorbent tubes were installed at the golf course's club house, approximately $1 \mathrm{~m}$ above ground. The coordinates of the sampling sites and further details are given in Table 1.



Figure 1. Map depicting a part of the Highveld area with the approximate locations of coal-fired power stations (pentagon symbol) and the locations of city centres (black dots).

Table 1. Coordinates of lichen and tree bark sampling and atmospheric mercury monitoring sites.

\begin{tabular}{|c|c|c|c|}
\hline Sampling Site & Lichen / Bark Sampling Dates & Location & Coordinates \\
\hline Pretoria - CSIR & Jul. 09 & $10 \mathrm{~km}$ east of city centre & 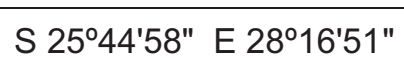 \\
\hline Pretoria - Hatfield & Nov. 07; Feb. 09; Jul. 09 & $5 \mathrm{~km}$ east of city centre & S 254' $45^{\prime \prime}$ E $28^{\circ} 14^{\prime} 21^{\prime \prime}$ \\
\hline Pretoria West & Feb. 09 & $4 \mathrm{~km}$ west of city centre & S $25^{\circ} 45^{\prime} 18^{\prime \prime}$ E $28^{\circ} 08^{\prime} 49^{\prime \prime}$ \\
\hline Witbank & Aug. 09; Nov. 09 & City centre & S 2552'54" E 29०12'58" \\
\hline
\end{tabular}

\subsection{Collection and preparation of lichen and tree bark samples}

Lichens of the genus Parmotrema austrosinense (Zahlbr.) Hale as well as tree bark were collected from Jacaranda mimosifolia trees at a height of at least $1.5 \mathrm{~m}$ to avoid contamination by soil. Samples were collected in the three suburbs of Pretoria as well as one site in the industrial city of Witbank (refer to Table 1). On arrival in the laboratory, samples were washed briefly with ultra pure water to remove dust, as described in literature (Walther et al., 1990 and Mitchell et al., 2000), heated at $60^{\circ} \mathrm{C}$ for $30 \mathrm{~min}$ to remove excess water and then dried at room temperature in a desiccator containing silica gel for $48 \mathrm{hr}$. Since temperatures up to $80^{\circ} \mathrm{C}$ have been reported for drying of lichens to be analysed for mercury content after washing (Sensen \& Richardson, 2002), $60{ }^{\circ} \mathrm{C}$ was considered to be a safe temperature to avoid volatilisation of absorbed mercury (Trüe et al., 2009). After grinding to a fine powder in an agate mortar, lichen and tree bark samples were stored frozen until analysis. Approximately $0.1 \mathrm{~g}$ of each sample was acid digested with $1 \mathrm{~mL}$ nitric acid $(65 \%$, mercury analysis grade, Sigma-Aldrich, Steinheim, Germany) and $1 \mathrm{~mL}$ hydrogen peroxide (30\%, puriss. p.a. ACS grade,

Sigma-Aldrich, Steinheim, Germany) using a MARS microwave digestion oven with $30 \mathrm{~mL}$

XPRESS digestion vessels. In order to optimise the digestion procedure, a stock of ground lichens was prepared and aliquots were prepared by microwave digestion at different holding temperatures $\left(120,160\right.$ and $\left.200{ }^{\circ} \mathrm{C}\right)$, as well as by acid leaching at room temperature for $24 \mathrm{hr}$. A temperature control program of $20 \mathrm{~min}$ ramp time from room temperature to $200^{\circ} \mathrm{C}$ and 20 min hold time at $200{ }^{\circ} \mathrm{C}$ was then applied for subsequent analyses. At the end of the digestion process, $1 \mathrm{~mL}$ hydrochloric acid (37\%, mercury analysis grade, Sigma-Aldrich, Steinheim, Germany) was added and the volume was made up to $10 \mathrm{~mL}$ with ultrapure water. One reaction vessel per batch was processed without lichen or tree bark addition as a laboratory blank, and after every 10 samples in a batch a BCR 482 (SigmaAldrich) lichen standard with a certified mercury concentration of $480 \mu \mathrm{g} \cdot \mathrm{kg}^{-1}$ was analysed as a quality control.

\subsection{Exposure and preparation of Anasorb C300 active sampling tubes}

Sealed glass Anasorb C300 tubes, containing $200 \mathrm{mg}$ of a Hopcalite-type metal oxide mixture, were broken open at the ends and connected to vacuum pumps by silicone tubing. The pumps were calibrated with a flow meter to operate at approximately 12 L.hr ${ }^{-1}$ and the amount of air drawn through each sorbent tube was measured by a gas meter. After exposure, the sorbent was poured into a plastic screw cap vial and $1 \mathrm{~mL}$ nitric acid and $1 \mathrm{~mL}$ hydrochloric acid were added. The vial was warmed slightly until a continuous stream of formed bubbles was visible. After dissolution of the sorbent granules, the sample volume was made up to $10 \mathrm{~mL}$ with 
water and the solution was sonicated for $30 \mathrm{~min}$ to remove elemental chlorine which had formed during dissolution of the Hopcalite.

The limit of detection of the CVAAS method had been determined as $0.1 \mu \mathrm{g} . \mathrm{L}^{-1}$, which made it necessary to collect at least $1 \mathrm{ng}$ of mercury in a sorbent tube to achieve this concentration after dissolution of the tube contents in $10 \mathrm{~mL}$ of acids. At an assumed atmospheric mercury concentration of $1 \mathrm{ng} \cdot \mathrm{m}^{-3}$, at least $1 \mathrm{~m}^{3}$ had to be drawn through a trap. A volume of $2 \mathrm{~m}^{3}$ was thus chosen, which was obtained during a seven day sampling period.

The performance of sorbent tube sampling has been assessed by comparison to an Opsis HG200 mercury analyser in a separate study (Trüe et al., 2010).

\subsection{Mercury analysis by CVAAS}

Analysis of digested plant samples as well as dissolved Hopcalite granules by cold vapour atomic absorption spectrometry (CVAAS) was performed using a Perkin Elmer Aanalyst 700 atomic absorption spectrometer with a FIAS 100 cold vapour generation unit. The carrier solution was $3.7 \%$ hydrochloric acid and the reduction solution contained $5 \%$ tin (II) chloride (Purum, Sigma-Aldrich, Steinheim, Germany), dissolved in the carrier solution.

Mercury calibration solutions with concentrations between 0.1 and $50 \mu \mathrm{g} . \mathrm{L}^{-1}$ were made from a $1003 \pm 3 \mu \mathrm{g} . \mathrm{L}^{-1} \mathrm{NIST}$ traceable standard (Spectrascan Teknolab AB). To match the standards to the sample matrix, each $10 \mathrm{~mL}$ of calibration standard solution contained $1 \mathrm{~mL}$ of nitric acid and hydrochloric acid, respectively. The concentration of atmospheric TGM was then calculated by dividing the amount of mercury absorbed in a sorbent tube by the recorded volume of air which passed through the tube during exposure.

\section{Results and Discussion}

\subsection{Lichen digestion parameter optimisation}

From the digestion optimisation experiments, a temperature of $200^{\circ} \mathrm{C}$ during microwave heating was found to yield the highest mercury recovery in subsequent CVAAS analyses of the digested lichen stock (Fig. 2). Higher digestion temperatures were not tested to avoid damage to the microwave vessels and possible loss of mercury vapour. Leaching of plant material in acid at room temperature was not considered for further experiments as the recovery of mercury was poor compared to microwave assisted digestion, as shown in Figure 2.

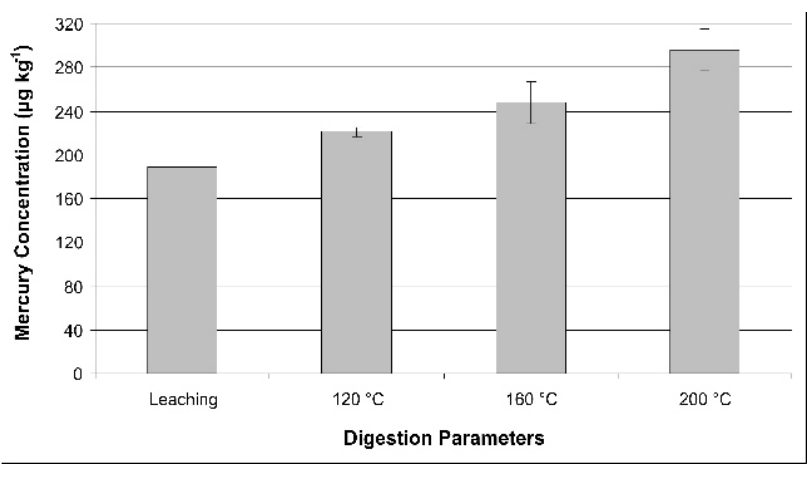

Figure 2. Mean mercury concentrations determined in lichen stock aliquots subjected to different digestion temperatures $(n=3)$, where error bars depict the standard deviation. In all cases $1 \mathrm{~mL}$ of nitric acid was used. The leaching experiment was conducted at room temperature, whilst the other temperatures were obtained by microwave heating.

Table 2. Average mercury concentrations with standard deviations found in lichens and tree bark from various locations. The number of samples analysed in each case is included in brackets.

\begin{tabular}{ccc}
\hline Location & $\begin{array}{c}\text { Mercury } \\
\text { Concentration } \\
\text { Lichens }\left(\mu \mathrm{kg} \cdot \mathrm{kg}^{-1}\right)\end{array}$ & $\begin{array}{c}\text { Mercury } \\
\text { Concentration Tree } \\
\text { Bark }\left(\mu \mathrm{kg} \cdot \mathrm{kg}^{-1}\right)\end{array}$ \\
\hline CSIR & $165 \pm 21(\mathrm{n}=11)$ & $72 \pm 24(\mathrm{n}=11)$ \\
Hatfield & $74 \pm 14(\mathrm{n}=14)$ & $28 \pm 11 \quad(\mathrm{n}=2)$ \\
Pretoria & $193 \pm 49(\mathrm{n}=9)$ & $50 \pm 14 \quad(\mathrm{n}=8)$ \\
West & & \\
Witbank & $228 \pm 53(\mathrm{n}=6)$ & $75 \pm 50 \quad(\mathrm{n}=7)$ \\
$\quad$ Golf & & \\
Course & & \\
\hline
\end{tabular}

\subsection{Lichens and tree bark}

A total of 29 samples of BCR 482 lichen standard were analysed together with lichen and bark samples. The average of $484 \mu \mathrm{g} \cdot \mathrm{kg}^{-1}$ was in good agreement with the target value of 480 $\mu \mathrm{g} \cdot \mathrm{kg}^{-1}$. A 2 SD limit of $66 \mu \mathrm{g} \cdot \mathrm{kg}^{-1}$ or $14 \%$ was calculated.

The foliose lichen Parmotrema Austrosinense (Zahlbr.) Hale was found to be the predominant species in Pretoria and the Highveld area and it offered the benefit of being relatively easy to separate from tree bark. The tree species Jacaranda mimosifolia was chosen as the host tree for lichen collection since it is prolific in the Highveld area and is easy to identify.

At all sampling sites across Pretoria and Witbank, the mercury concentration in lichens was consistently higher than in Jacaranda tree 
bark, as shown in Table 2. This may be due to the high surface area of lichens and resulting high air exchange, as well as their dependence on the atmospheric environment as the main source of nutrients. Tree bark was therefore considered to be a less sensitive indicator for atmospheric mercury pollution and was not included in further evaluations. It is important to note, however, that the mercury concentrations in tree bark followed the geographical trend of those determined in lichens. Lichen and bark samples were collected on the dates shown in Table 2.

Lichen samples collected in Hatfield showed a significantly lower concentration $(p<0.01$, ANOVA single factor, $99 \%$ confidence limit) of mercury than both those collected in Pretoria West and at the CSIR. This was surprising, since the sampling sites in Hatfield were lying between Pretoria West and the CSIR, only a few kilometres apart, and the concentrations of mercury in lichen samples from Pretoria West and the CSIR premises did not differ significantly $(p=0.1$, ANOVA single factor, $99 \%$ confidence limit). The reason for the low mercury concentrations in plant material in Hatfield is unknown, although it is hypothesised that vehicle exhaust gases may affect lichen physiology since lichens are known to be sensitive to atmospheric pollutants (Conti \& Cechetti, 2001). It should be noted that lichen $\mathrm{Hg}$ levels relate to historical, long term ambient $\mathrm{Hg}$ levels, which may differ from current, short term ambient $\mathrm{Hg}$ levels. The difference in sampling heights may also have had an effect, especially in the city centre, as buildings impact on the diffusion of air pollutants. Witbank had the highest average mercury concentration in both lichens and tree bark, but the standard deviation was also high.

\subsection{Atmospheric mercury analysis in Pretoria and Witbank}

Sampling with Anasorb C300 tubes was performed for seven days per tube over several weeks at all sites. Each site was equipped with two pumps and sorbent tubes. Due to the limited number of pumps available, they had to be moved between locations, resulting in differing exposure dates. Therefore, results obtained from sampling in Witbank were compared only to those obtained at the CSIR, where the pumps were operated continuously. Results are shown in Figures 3 and 4. Average TGM concentrations in ambient air at the three Pretoria suburban sites, as determined by this semi-continuous spectroscopic method, ranged between 1.6 and
$2.5 \mathrm{ng} \cdot \mathrm{m}^{-3}$, while an average of $1.7 \mathrm{ng} \cdot \mathrm{m}^{-3}$ was measured in Witbank over the sampling interval.

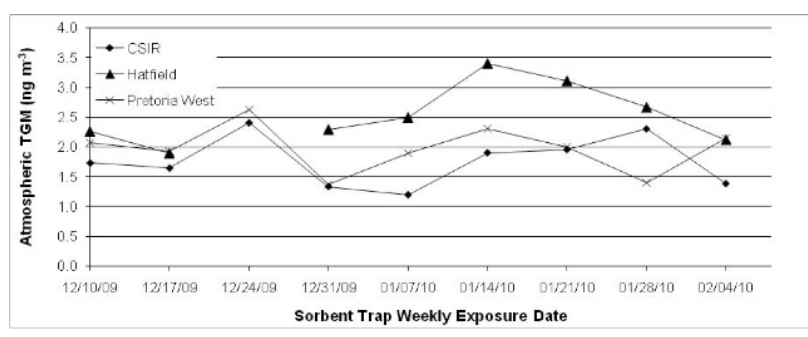

Figure 3. Comparison of the atmospheric mercury concentrations measured at the CSIR, Hatfield and Pretoria West using Hopcalite sampling. Mean of duplicate values shown (dates given in MM/DD/YY format).

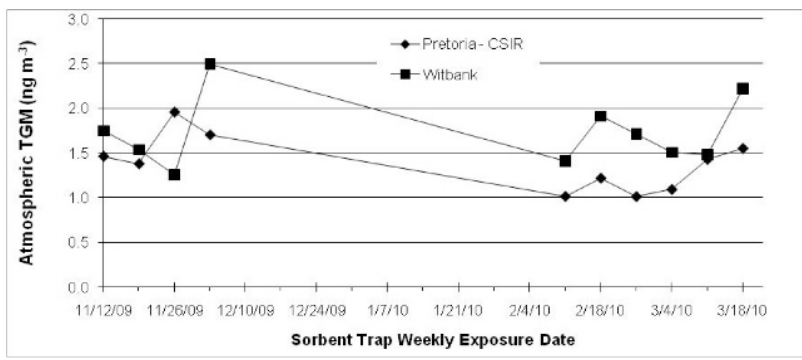

Figure 4. Atmospheric mercury concentrations measured at the CSIR and in Witbank using Hopcalite sampling. Mean of duplicate values shown (dates given in MM/DD/YY format).

Within Pretoria, significantly higher atmospheric mercury concentrations were measured in Hatfield than in other areas $(p<0.01$, ANOVA single factor, $99 \%$ confidence limit), which is in contrast to the trend found for $\mathrm{Hg}$ in lichens (Fig. 5 ). It must be noted that this difference could well have arisen due to the difference in sampling interval represented by lichens and the sorbent tubes, as the $\mathrm{Hg}$ content in lichens indicate integrative values over extended time intervals, whilst the sorbent tubes sampled over a period of a week.

Atmospheric mercury concentrations near a coal-fired power station in Pretoria West were not significantly higher than those determined at the CSIR premises $(p=0.304$, ANOVA single factor, $99 \%$ confidence limit). A comparison between concentrations determined at the CSIR and in Witbank also showed no significant difference $(p=0.04$, ANOVA single factor, $99 \%$ confidence limit). 




Figure 5. Comparison between the average mercury concentration in ambient air during the monitoring period (line graph) and lichens (bar graph, where the standard deviation is shown by means of error bars and the number of samples for each site is given in Table 2).

\section{Conclusions}

During atmospheric mercury monitoring from November 2009 to February 2010, air was found to be less polluted with atmospheric mercury in Pretoria and Witbank than in two large cities worldwide, namely Toronto (Song et al., 2009) and Beijing (Liu et al., 2002). Whilst neither the number of sampling locations nor the length of the monitoring interval allow deductions to be drawn regarding the atmospheric total gaseous mercury concentration in South Africa as a whole, the relatively low concentrations found in the industrial centre of Witbank (1.7 0.4 ng. ${ }^{-3}$ ), as well as in the suburbs of Pretoria, namely Hatfield (2.6 $0.6 \mathrm{ng}^{-3} \mathrm{~m}^{-3}$ ), Pretoria West (2.0 0.4 ng. $\mathrm{m}^{-3}$ ) and Brummeria (1.8 $0.4 \mathrm{ng} \cdot \mathrm{m}^{-3}$ ), suggest that mercury emissions may not be as high as published values based on calculated emissions factors, which list South Africa as the country with the second highest $\mathrm{Hg}$ emissions in the world (Pacyna \& Pacyna, 2002) and may be more in line with those published later (Masekoameng, 2010).

The use of actively pumped Anasorb C300 mercury sorbent tubes made simultaneous atmospheric mercury monitoring at various locations possible, which could not have been achieved with a single semi-continuous mercury analyser. Our study is the first in South Africa to determine mercury levels in lichens and tree bark. Further studies should be undertaken to encompass a wider geographical area in order to further assess any spatial trends in this regard.

\section{Acknowledgements}

The authors would like to thank Dr. Luciana
Zedda from the Friedrich Wilhelms Universität in Bonn, Germany for identifying the lichen species. Maanda Rasuba from the CSIR Built Environment is thanked for assisting with the statistical analyses and Mogesh Naidoo is thanked for preparing the map of the Pretoria Witbank area. Juan Mostert from the Department of Agriculture and Environment of the City of Tshwane is thanked for providing a shelter for measuring equipment in Pretoria West. Meteorological data for Witbank was supplied by the South African Weather Service.

The work was funded by the CSIR Strategic Research Panel and a National Research Foundation / Norway collaborative project.

\section{References}

Becnel J., Falgeust C., Cavalier T., Gauthreaux K. Landry F., Blanchard M., Beck M.J. and Beck N.J. 2004, Microchemical Journal, 78:205-210.

Carpi A. 1997, Water, Air and Soil Pollution, 98:241254.

Conti M.E. and Cechetti G. 2001, Environmental Pollution, 114:471-492.

Ebinghaus R., Jennings S.G., Schroeder W.H., Berg T., Donaghy T., Guentzel J., Kenny C., Kock H.H., Kvietkus K., Landing W., Muhleck T., Munthe J., Prestbo E.M., Schneeberger D., Slemr F., Sommar J., Urba A., Wallschlaeger D. and Xiao Z. 1999, Atmospheric Environment, 33:3036-3073.

European Communities, 2002, Ambient air pollution by mercury $(\mathrm{Hg})$, Position Paper, 17 October 2001, ISBN 92-894-4260-3. Page 128.

Forbes P.B.C., Thanjekwayo M., Okonkwo J.O., Sekhula M. and Zvinowanda C. 2009, Fresenius Environmental Bulletin, 18:609-614.

Health and Safety Executive, 2002, Methods for the Determination of Hazardous Substances 16/2: Mercury and its Divalent Compounds in Air, HSE Books, Suffolk, UK.

Liu S., Nadim F., Perkins C., Carley R.J., Hong G.E., Lin Y. and Chen L. 2002, Chemosphere, 48:97-107.

Machado A., Šleijkovec Z., Van Elteren J.T., Freitas M.C. and Baptista M.S. 2006, Journal of Atmospheric Chemistry, 53:237-249.

Masekoameng K.E., Leaner J. and Dabrowski J. 2010, Atmospheric Environment, 44:3007-3014.

Mitchell A., Steib E., King A., O'Rourke S., Gauthreaux K. and Beck J.N. 2000, Microchemical Journal, 64:271-276. 
Monna F., Poujol M., Losno R., Dominik J., Annegarn, H. and Coetzee H. 2006, Atmospheric Environment, 40:6554-6566.

$\mathrm{NIOSH}$ Method 6009, Edition 2.1994. In NIOSH Manual of Analytical Methods, Fourth Edition.

Pacyna E.G., Pacyna J.M., Steenhuisen F. and Wilson S. 2006, Atmospheric Environment, 40:4048 -4063 .

Pacyna E.G. and Pacyna J.M. 2002, Water, Air and Soil Pollution, 137:49-165.

Panichev N. and McCrindle R.I. 2004, Journal of Environmental Monitoring, 6:121-123.

Rathje A., Marcero D.H. and Dattilo D. 1974, American Industrial Hygiene Association Journal, 35:571-575.

Sensen M. and Richardson D.H.S. 2002, The Science of the Total Environment, 293:31-45.

Song X., Cheng I., and Lu J. 2009, Journal of Environmental Monitoring, 11:660-669.

Trüe A., Forbes P.B.C., Panichev N. and Okonkwo O.J. 2010, Fresenius Environmental Bulletin, 19 (12a):3007-3012.

Trüe A., Forbes P.B.C., Panichev N. and Okonkwo O.J. 2009, National Association of Clean Air Conference Proceedings, Vanderbijlpark, South Africa, 14-16 October 2009.

Walther D.A., Ramelow G.J., Beck J.N., Young J.C., Callahan J.D. and Marcon M.F. 1990, Water, Air and Soil Pollution, 53:189-200. 